\title{
Separation of Glycyrrhizic Acid Using Smart Polymer Based Aqueous Two-Phase Systems
}

\author{
Jiang $\mathrm{WU}^{1, \mathrm{a},{ }^{*}}$
}

${ }^{1}$ College of Agronomy \& Resources and Environment, Tianjin Agricultural University, Tianjin 300384, People's Republic of China

awujiangjack@163.com

${ }^{*}$ Corresponding author

Keywords: Glycyrrhizic acid, Aqueous two-phase system, $\mathrm{EO}_{60} \mathrm{PO}_{40}$, Separation.

\begin{abstract}
In this paper, glycyrrhizic acid was separated using ethylene oxide / propylene oxide copolymer $\left(\mathrm{EO}_{60} \mathrm{PO}_{40}\right)$ and $\mathrm{K}_{2} \mathrm{HPO}_{4}$ aqueous two-phase systems (ATPS). The influence of the content of $\mathrm{EO}_{60} \mathrm{PO}_{40}$ and $\mathrm{K}_{2} \mathrm{HPO}_{4}$ and temperature was studied. The results showed that the optimal separation conditions were: $30 \% \mathrm{EO}_{60} \mathrm{PO}_{40}, 24 \% \mathrm{~K}_{2} \mathrm{HPO}_{4}, 53^{\circ} \mathrm{C}$ of extraction temperature, $1.5 \mathrm{~h}$ of extraction time. This separation process provides a simple and convenient method for extracting glycyrrhizic acid.
\end{abstract}

\section{Introduction}

Glycyrrhiza uralensis Fisch. is a kind of Chinese herbal medicine with great application value (Zeng et al. 1988). Glycyrrhizic acid (GA) is an important component in G. uralensis for its biological activities, such as immune-stimulating activities, anti-inflammatory and antitumor (Cherng et al. 2004; Hoever et al. 2005; Sasaki et al. 2002; Shibata 2000; Van Rossum et al. 1999).

It was reported that GA was separated by using an ion-exchange chromatographic method (Baltina et al. 1993), and 82.3\% of GA was purified. Another reported method was the ultrafiltration (Pan et al. 2000) and 52.3\% of GA was separated.

The aim of this present study was to develop a convenient method of separating GA from licorice extract. Smart aqueous two-phase extraction (ATPE) was used in this study to separate GA. $\mathrm{EO}_{60} \mathrm{PO}_{40}$ is a kind of thermosensitive polymer. When adjusting the temperature change, the phase separation of the system of $\mathrm{EO}_{60} \mathrm{PO}_{40} / \mathrm{K}_{2} \mathrm{HPO}_{4}$ could be observed.

\section{Experimental Methods}

\section{Materials}

Licorice root was purchased from Chinese herbal medicine market. $\mathrm{EO}_{60} \mathrm{PO}_{40}$ was obtained from Shanghai and Sichuan trade co., LTD. Other chemical reagents were obtained from Beijing Dingguo Changsheng Biotechnology CO., LTD.

\section{Procedures}

\section{Standard Curve Drawing}

The ammonium salt of ammonium glycyrrhizinate was precisely weighted $0.0525 \mathrm{~g}$, dissolved with $50 \%$ ethanol and transferred to a $50 \mathrm{~mL}$ volumetric flask, and then the beaker was moistened with $50 \%$ ethanol, washed for 3 times, transferred the fluid-transfer fluid into a $50 \mathrm{~mL}$ volumetric flask, and adding 50\% ethanol to the scale line and shaking it well (short for A solution). $0 \mathrm{~mL}, 1 \mathrm{~mL}, 2 \mathrm{~mL}, 3$ $\mathrm{mL}, 4 \mathrm{~mL}$ and $5 \mathrm{~mL}$ of solution A were absorbed by the pipette and added to the $50 \mathrm{~mL}$ volumetric flask respectively. 50\% ethanol was diluted to the scale line and shaken evenly. The absorbance of a series of gradient solutions was determined by ultraviolet-visible spectrophotometer at $253 \mathrm{~nm}$ wavelength and $50 \%$ ethanol as reference solution. 


\section{Preparation of Concentrated Liquorice Solution}

$50 \mathrm{~g}$ of liquorice was added to $100 \mathrm{ml}$ distilled water and refluxed for $1.5 \mathrm{~h}$. Then the extracting solution was centrifuged at a speed of $3000 \mathrm{r} / \mathrm{min}$ for $10 \mathrm{~min}$ for the supernatant.

\section{Aqueous Two-Phase Extraction System}

The total mass of $\mathrm{EO}_{60} \mathrm{PO}_{40} / \mathrm{K}_{2} \mathrm{HPO}_{4}$ system was $10 \mathrm{~g}$, in which glycyrrhiza concentrate was $4 \mathrm{~g}$. This system was mixed well and centrifuged for the upper and lower phases. Then the upper phase was subjected to temperature induction, the system was automatically divided into two phases, whose upper phase was $\mathrm{EO}_{60} \mathrm{PO}_{40}$ phase and lower phase was water phase. This water phase contained glycyrrhizic acid which could be detected at $253 \mathrm{~nm}$ wavelength.

\section{Effect of EO60PO40 Mass Fraction on Extraction Results}

The specific operation method was shown in Table 1 below. 4 g glycyrrhiza concentrate was added into this system.

Table 1 Aqueous two-phase extraction system different mass fraction of EO60PO40

\begin{tabular}{cccccc}
\hline Numbering & 1 & 2 & 3 & 4 & 5 \\
\hline $\mathrm{K}_{2} \mathrm{HPO}_{4} / \mathrm{g}$ & 2.4 & 2.4 & 2.4 & 2.4 & 2.4 \\
$\mathrm{EO}_{60} \mathrm{PO}_{40} / \mathrm{g}$ & 2.0 & 2.5 & 3.0 & 3.5 & 4.0 \\
$\mathrm{H}_{2} \mathrm{O} / \mathrm{g}$ & 5.6 & 5.1 & 4.6 & 4.1 & 3.6 \\
$\mathrm{EO}_{60} \mathrm{PO}_{40} / \%$ & $20 \%$ & $25 \%$ & $30 \%$ & $35 \%$ & $40 \%$ \\
\hline
\end{tabular}

\section{Effect of K2HPO4 Mass Fraction on Extraction Results}

The specific operation method was shown in Table 2 below. 4 g glycyrrhiza concentrate was added into this system.

Table 2 Aqueous two-phase extraction system different mass fraction of $\mathrm{K}_{2} \mathrm{HPO}_{4}$

\begin{tabular}{cccccc}
\hline Numbering & 1 & 2 & 3 & 4 & 5 \\
\hline $\mathrm{EO}_{60} \mathrm{PO}_{40} / \mathrm{g}$ & 3.0 & 3.0 & 3.0 & 3.0 & 3.0 \\
$\mathrm{~K}_{2} \mathrm{HPO}_{4} / \mathrm{g}$ & 1.8 & 2.0 & 2.2 & 2.4 & 2.6 \\
$\mathrm{H}_{2} \mathrm{O} / \mathrm{g}$ & 5.2 & 5.0 & 4.8 & 4.6 & 4.4 \\
$\mathrm{~K}_{2} \mathrm{HPO}_{4} / \%$ & $18 \%$ & $20 \%$ & $22 \%$ & $24 \%$ & $26 \%$ \\
\hline
\end{tabular}

\section{Effect of Temperature on Extraction Results}

For this study, the aqueous two-phase extraction system was composed as followed: $30 \% \mathrm{EO}_{60} \mathrm{PO}_{40}$ ( $3.0 \mathrm{~g}), 24 \% \mathrm{~K}_{2} \mathrm{HPO}_{4}(2.4 \mathrm{~g}), 46 \% \mathrm{H}_{2} \mathrm{O}$ (4.6 g). Then $4 \mathrm{~g}$ glycyrrhiza concentrate was added into this system. The temperature gradient was shown in Table 3.

Table 3 Effect of temperature gradient on extraction results

\begin{tabular}{cccccc}
\hline Numbering & 1 & 2 & 3 & 4 & 5 \\
\hline $\begin{array}{c}\text { Temperature } \\
1{ }^{\circ} \mathrm{C}\end{array}$ & 47 & 50 & 53 & 56 & 59 \\
\hline
\end{tabular}




\section{Effect of Time on Extraction Results}

The extraction system was accordance with Effect of temperature on extraction results. The extraction temperature was $53^{\circ} \mathrm{C}$. The extraction time was $0.5 \mathrm{~h}, 1 \mathrm{~h}, 1.5 \mathrm{~h}$ and $2 \mathrm{~h}$.

\section{Results and Analysis}

\section{Effect of $\mathrm{EO}_{60} \mathrm{PO}_{40}$ Mass Fraction on Extraction Results}

When the mass fraction of $\mathrm{K}_{2} \mathrm{HPO}_{4}$ was $24 \%$, the effect on the extraction rate of glycyrrhizic acid was investigated under the change of the $\mathrm{EO}_{60} \mathrm{PO}_{40}$ mass fraction. The results were shown below (Fig.1).

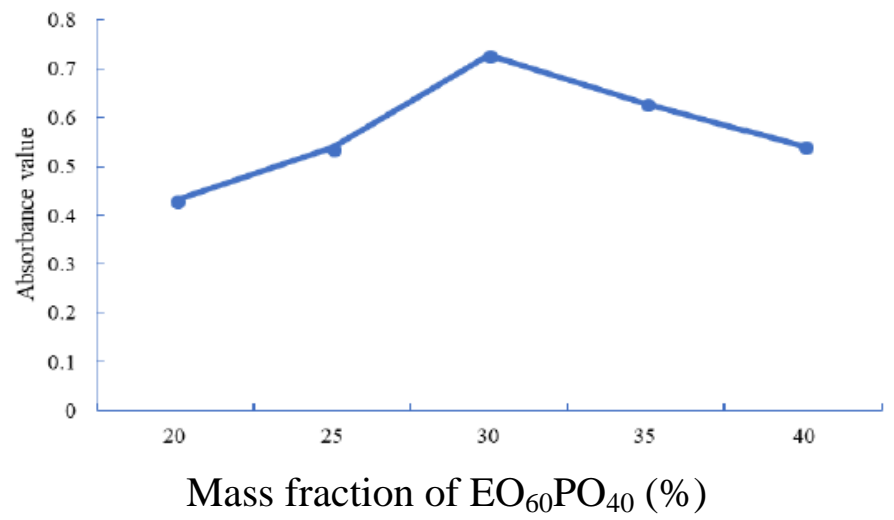

Fig. 1 Absorbance value of glycyrrhizin solution extracted by different mass fraction of $\mathrm{EO}_{60} \mathrm{PO}_{40}$

As shown in Fig. 1, when the mass fraction of $\mathrm{EO}_{60} \mathrm{PO}_{40}$ was between $20 \%$ and $30 \%$, the absorbance value of the solution measured gradually increased. And when the mass fraction of $\mathrm{EO}_{60} \mathrm{PO}_{40}$ increased to $30 \%$, the absorbance value of solution decreased gradually. Therefore, the $\mathrm{EO}_{60} \mathrm{PO}_{40}$ mass fraction of glycyrrhizic acid in liquorice was $30 \%$.

\section{Effect of $\mathrm{K}_{2} \mathrm{HPO}_{4}$ mass Fraction on Extraction Results}

When $\mathrm{EO}_{60} \mathrm{PO}_{40}$ mass fraction was $30 \%$, the effect of $\mathrm{K}_{2} \mathrm{HPO}_{4}$ mass fraction on the extraction rate of glycyrrhizic acid was investigated. The results were shown in Fig. 2.

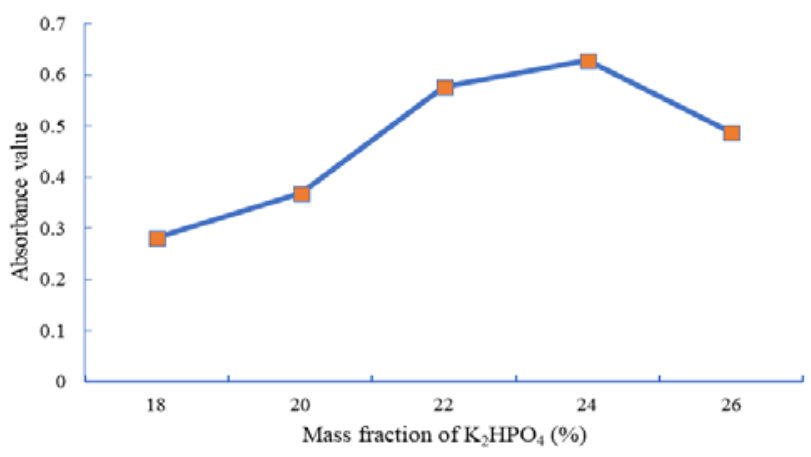

Fig. 2 Absorbance value of glycyrrhizin solution extracted by different mass fraction of $\mathrm{K}_{2} \mathrm{HPO}_{4}$

As shown in Fig. 2, when the mass fraction of $\mathrm{K}_{2} \mathrm{HPO}_{4}$ was between $18 \%$ and $24 \%$, the absorbance value of the solution measured gradually increased. And when the mass fraction of $\mathrm{K}_{2} \mathrm{HPO}_{4}$ increased to $24 \%$, the absorbance value of solution decreased gradually. Therefore, the $\mathrm{K}_{2} \mathrm{HPO}_{4}$ mass fraction of glycyrrhizic acid in liquorice was $24 \%$.

\section{Effect of Temperature on Extraction Results}

When $\mathrm{EO}_{60} \mathrm{PO}_{40}$ mass fraction was $30 \%$ and $\mathrm{K}_{2} \mathrm{HPO}_{4}$ mass fraction was $24 \%$, the effects of temperature changes on the extraction rate of glycyrrhizin were investigated. 


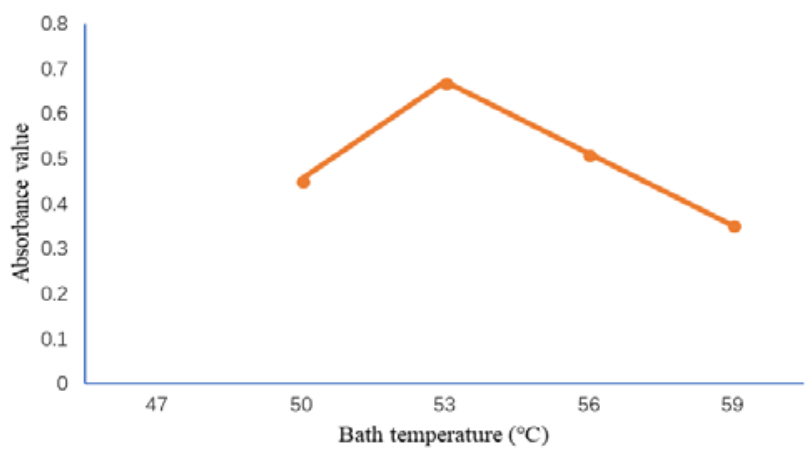

Fig. 3 The absorbance of glycyrrhizin solution at different water bath temperature

As shown in Fig. 3, when the temperature was $47^{\circ} \mathrm{C}$, the solution is mixed. When the temperature was less than $53^{\circ} \mathrm{C}$, with the increase of temperature, the absorbance of glycyrrhizic acid solutions was gradually increased. When the temperature was more than $53^{\circ} \mathrm{C}$, the absorbance glycyrrhizic acid solutions was decreased. So, the best extraction temperature was $53^{\circ} \mathrm{C}$.

\section{Effect of Extraction Time on Extraction Results}

In the conditions of $\mathrm{EO}_{60} \mathrm{PO}_{40}$ mass fraction $30 \%, \mathrm{~K}_{2} \mathrm{HPO}_{4}$ mass fraction $24 \%$, extraction temperature $53{ }^{\circ} \mathrm{C}$, the effect of extraction time on extraction efficiency was investigated.

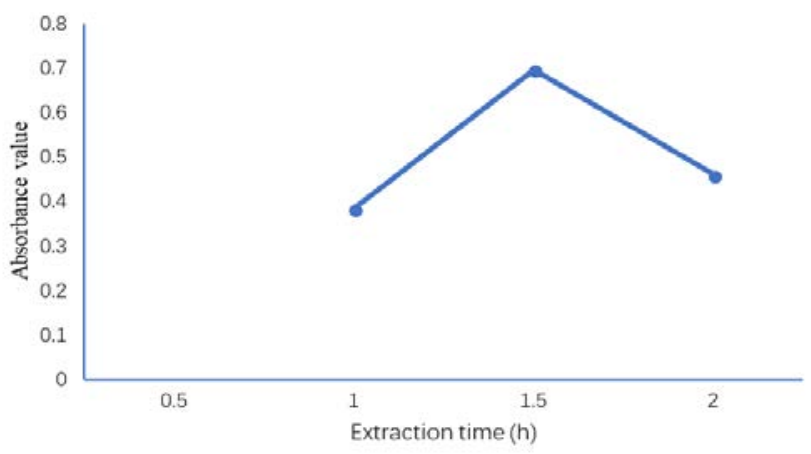

Fig. 4 The absorbance of extraction solution under different bath time

As shown in Fig. 4, when the extraction time was $1.5 \mathrm{~h}$, the absorbance value of glycyrrhizin solution was the highest.

\section{Conclusion}

The conclusion was drawn by studying the smart aqueous two-phase extraction system of glycyrrhizin. The best extraction conditions were: $30 \% \mathrm{EO}_{60} \mathrm{PO}_{40}, 24 \% \mathrm{~K}_{2} \mathrm{HPO}_{4}, 53{ }^{\circ} \mathrm{C}$ of extraction temperature, $1.5 \mathrm{~h}$ of extraction time.

\section{Acknowledgement}

This work was supported by Tianjin Municiprl Educrtion Commission (Grant number: 20140605).

\section{References}

[1] L. Zeng, S.H. Li, Z.C. Lou, Morphological and histological studies of Chinese licorice, Yao Xue Xue Bao 23 (1988) 200-208.

[2] J.M. Cherng, H.J. Lin, Y.H. Hsu, M.S. Hung, J.C. Lin, A quantitative bioassay for HIV-1 gene expression based on UV activation: effect of glycyrrhizic acid, Antiviral Research 62 (2004) 27-36. 
[3] G. Hoever, L. Baltina, M. Michaelis, R. Kondratenko, L. Baltina, G.A. Tolstikov, H.W. Doerr, J. Cinatl, Antiviral activity of glycyrrhizic acid derivatives against SARS-Coronavirus, Journal of Medicinal Chemistry 48 (2005) 1256-1259.

[4] H. Sasaki, M. Takei, M. Kobayashi, R.B. Pollard, F. Suzuki, Effect of glycyrrhizin, an active component of licorice roots, on HIV replication in cultures of peripheral blood mononuclear cells from HIV-seropositive patients, Pathobiology 70 (2002) 229-236.

[5] S. Shibata, A drug over the millennia: Pharmacognosy, chemistry, and pharmacology of licorice Yakugaku Zasshi, Journal of the Pharmaceutical Society of Japan 120 (2000) 849-862.

[6] T.G.J. Van Rossum, A.G. Vulto, W.C.J. Hop, J.T. Brouwer, H.G.M. Niesters, S.W. Schalm, Intravenous glycyrrhizin for the treatment of chronic hepatitis C: A double-blind, randomized, placebo-controlled phase I/II trial, Journal of Gastroenterology and Hepatology 14 (1999) 1093-1099.

[7] L.A. Baltina, S.A. Ryzhova, E.V. Vasileva, A.P. Kapina, G.A. Tolstikov, Transformations of Glycyrrhizic Acid .6. New Method of Preparation of Carboxy-Protected Glycopeptides, Russian Journal of General Chemistry 63 (1993) 2140-2147.

[8] X.J. Pan, H.Z. Liu, G.H. Jia, Y.Y. Shu, Microwave-assisted extraction of glycyrrhizic acid from licorice root, Biochemical Engineering Journal 5 (2000) 173-177. 